\title{
Spontaneous Regression of Metastatic Malignant Melanoma
}

GEORGE R. MIKHAIL, M.D.

DAVID C. GORSULOWSKY, M.D.

\section{CASE REPORT}

\begin{abstract}
Spontaneous regression of metastatic malignant melanoma is rare. A case is presented here. The primary lesion, a lentigo maligna melanoma of the face, recurred after excision and metastasized to the parotid and upper cervical lymph nodes, and to the lungs. The patient declined further therapy. There was no clinical or radiologic evidence of metastasis 1 year later.
\end{abstract}

Although rare, spontaneous regression of cancers has been documented. ${ }^{1,2}$ "Spontaneous regression" means partial or complete resolution of a tumor in the absence of any treatment or with therapy that is inadequate to alter the course of the malignancy. ${ }^{3}$

The first report of complete regression of metastatic malignant melanoma in the English literature appears to have been by Bennett in 1899. ${ }^{4}$ Bodurtha reviewed 29 cases in 1979. Regression of cutaneous or lymph node metastases ${ }^{5}$ was more frequent than regression of visceral metastases. ${ }^{6}$ The patient presented here had a lengito malignant melanoma of the face that metastasized to the regional lymph nodes and the lungs. The metastatic lesions resolved spontaneously after removal of the cutaneous lesion.

George R. Mikhail, M.D., is Director, Mohs Micrographic Surgery Section, Department of Dermatology, Henry Ford Hospital, Detroit, Michigan.

David C. Gorsulowsky, M.D., is Instructor, Department of Dermatology, University of Michigan Medical School, Ann Arbor, Michigan.

Address reprint requests to George R. Mikhail, M.D., Department of Dermatology, Henry Ford Hospital, 2799 West Grand Boulevard, Detroit, MI 48202.

\section{CASE REPORT}

A 77-year-old woman was first seen in June 1978 with a 25-year history of a slowly enlarging, black lesion of the face. The lesion extended from the palpebral conjunctiva of the right lower eyelid superiorly to the mandibular margin inferiorly, and from the right nasolabial fold medially to the preauricular area laterally. Two $1-\mathrm{cm}$, lightly pigmented nodules were present in the infraorbital area and cheek (Fig. 1). There were no lymphadenopathies or significant findings, and the chest $x$-rays did not show any abnormalities. The nodules, removed as biopsies, showed a spindle cell malignant melanoma, Clark level IV, $2.8 \mathrm{~mm}$ maximum thickness. Mohs microscopically controlled surgery, fresh tissue technique was undertaken in June 1978 to ablate the lesion, with the exception of the part involving the eyelid margin and palpebral conjunctiva which was deferred to a later date in order to avoid exposure and injury to the globe. A splitthickness autograft was used to cover the wound.

In April 1979, 10 months after the initial excision, three new pigmented plaques had developed adjacent to the superior, anterior, and inferior margins of the graft. They were $0.5,0.7$, and $1.0 \mathrm{~cm}$ in size. Biopsies showed malignant melanoma, Clark level II, $0.2 \mathrm{~mm}$ thick. It was noted that there was a $1-\mathrm{cm}$, subcutaneous mass in the parotid gland and several smaller masses, presumably lymph nodes, could be palpated in the submandibular region. The parotid mass was excised and proved to be a lymph node with metastatic melanoma (Fig. 2). Radiographs of the chest showed nodules in both lungs which were considered compatible with a metastatic tumor (Fig. 3). The patient consented to have 


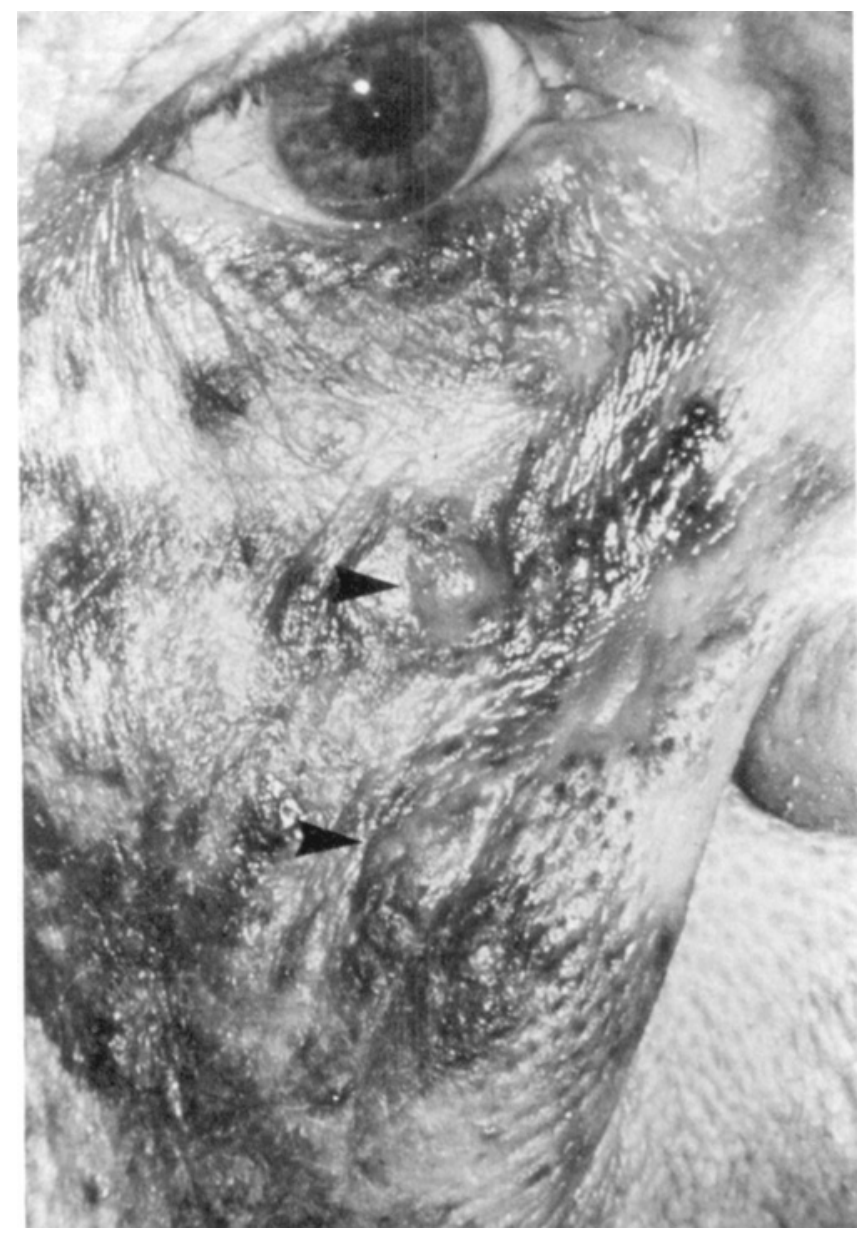

FIGURE 1. Extensive lentigo maligna of right side of face and lower eyelid with two nodules of malignant melanoma (arrowheads).

the cutaneous and conjunctival lesions excised, but declined further studies or therapy. She was then kept under periodic observation.

When seen in March 1980, about 12 months after the last excision, the lymph nodes had become nonpalpable, and the lesions in the lungs had cleared (Fig. 4). The patient remained free of any signs or symptoms of melanoma until she expired from other causes in May 1985, about 6 years after the initial evaluation.

\section{COMMENTS}

Spontaneous partial to complete regression of primary cutaneous melanoma is not uncommon. It occurs in up to $15 \%$ of cases. ${ }^{7,8}$ This may account for presence of metastases in the absence of an obvious primary lesion on the skin. Of the first 561 patients with melanoma observed in the M.D. Anderson

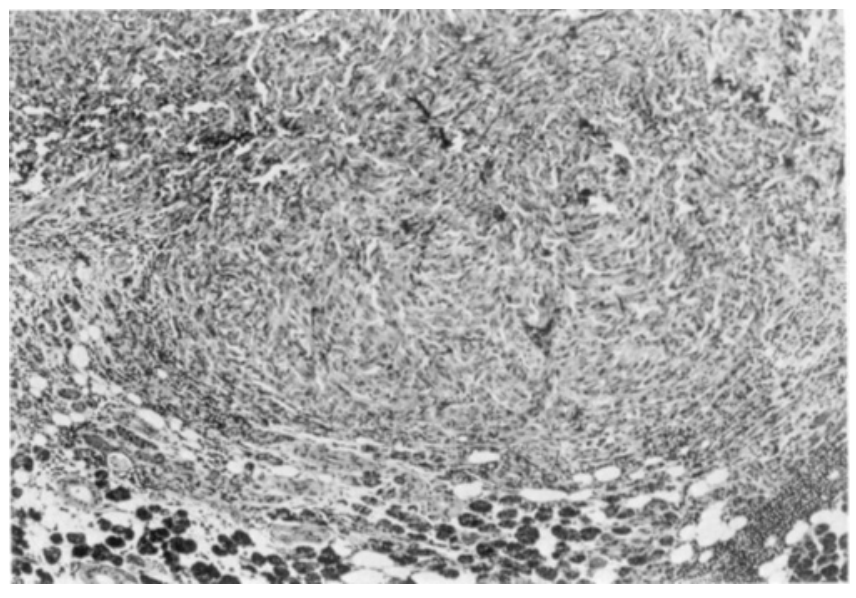

FIGURE 2. Metastatic malignant melanoma in parotid lymph node. Remnants of lymphoid tissue and part of parotid gland are in lower part (original magnification $x$ 90).

Hospital, $40(8.7 \%)$ had such lesions. ${ }^{9}$ However, spontaneous regression of metastatic melanoma is rare; only 29 cases are on record. ${ }^{5,6,10-38}$ Although the incidence of such a phenomenon is not known, studies of reported series indicate that it is in the order of $0.22-0.25 \% .^{6,35}$ Bodurtha has analyzed 29 documented cases. ${ }^{6}$

Some pertinent data are summarized here. Regression of cutaneous or lymph node metastases (26 cases) was more frequent than regression of visceral metastases. Radiologically demonstrated pulmonary metastases regressed in five cases. The longterm survival ( 5 years or longer) of spontaneously regressing melanoma in this series was substantially superior to that in cases with recurrent disease. As has been pointed out, spontaneous regression is not synonymous with cure. ${ }^{3}$ Six of 19 longterm survivors died with recurrent disease. ${ }^{6}$

The mechanisms of spontaneous regression of melanoma are as yet unclear. They have been related to immunologic, endocrine, pigment metabolic, intracellular, nutritional, and carcinogenic factors. ${ }^{35}$ There is also evidence that spontaneous remission of primary cutaneous and metastatic malignant melanoma occurs mainly through an immune mechanism. ${ }^{6,34-37}$ Rohdenburg collected 302 malignant tumors of various types in which temporary or permanent regression of a malignant growth occurred. The greatest number of spontaneous regressions followed incomplete surgical removal of the tumor or acute infections with prolonged pyrexia. ${ }^{38}$

In the case presented here, metastasis to a regional lymph node was proved histologically. Although there was no histologic evidence that the 


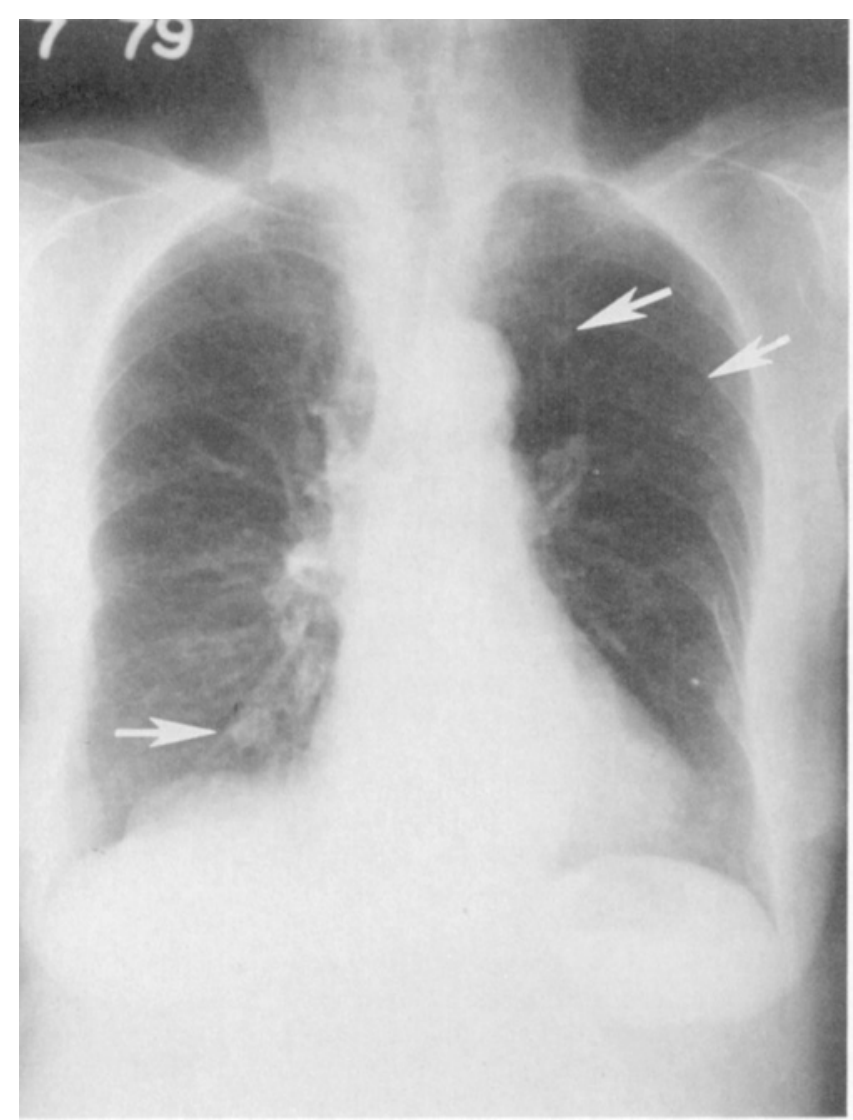

FIGURE 3. Radiogram of chest in May 1979. There are radiopaque nodules (arrows) in the base of right lung and in the upper lobe of left lung interpreted "compatible with metastases."

nodules in the lungs were metastatic melanoma, the radiographic findings were compatible with this diagnosis, especially in view of the patient's history. This assumption has already been accepted in five cases. ${ }^{5,6,18,25,27,29}$ It is also reasonable to assume that the metastases were in transit or were undetectable during the initial evaluation of the case. As

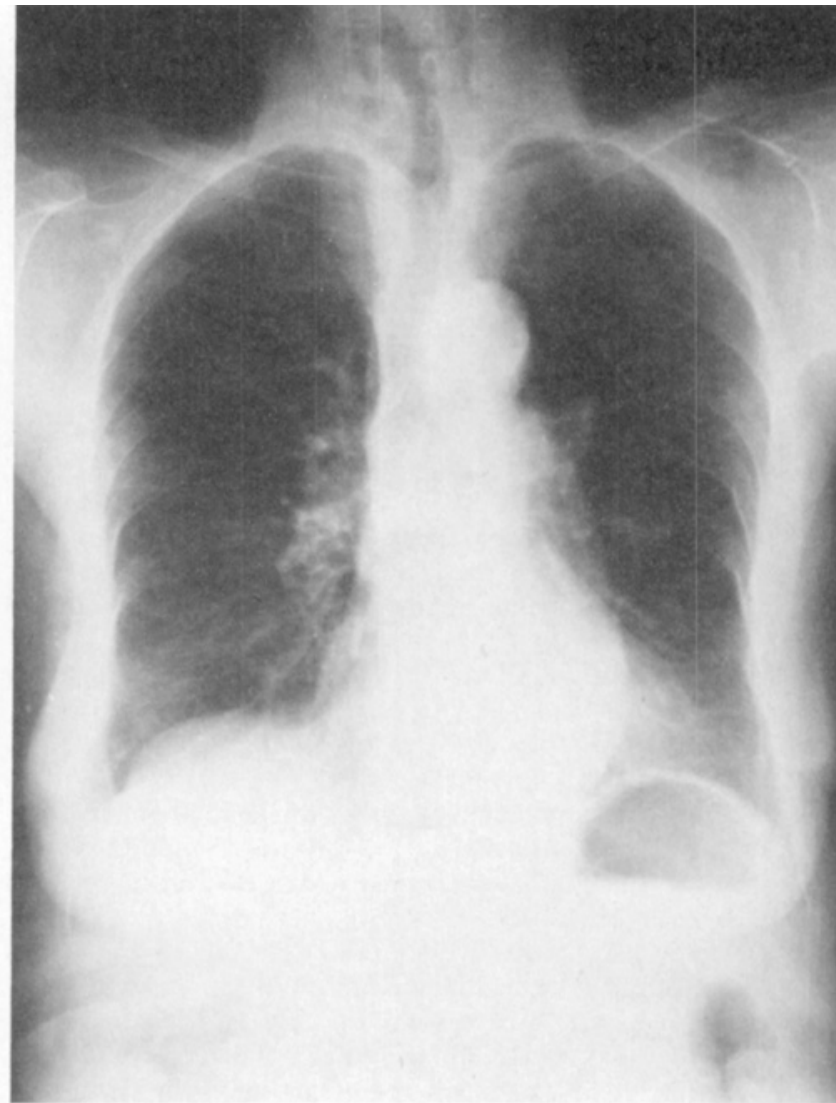

FIGURE 4. Radiogram of chest in March 1980. The opacities seen in Figure 3 have resolved.

the lymph node metastases and the pulmonary lesions regressed at 12 months after excision of the recurrent cutaneous melanoma and the parotid lymph node metastasis, it is possible that the favorable outcome might have resulted from stimulation of the immune mechanism by the surgery as has been suggested by Rohdenburg. ${ }^{38}$

\section{REFERENCES}

1. Everson TC, Cole WH. Spontaneous Regression of Cancer. Philadelphia, WB Saunders Co, 1966, pp 1-10, 164-220.

2. Boyd W. The Spontaneous Regression of Cancer. Springfield, Illinois, Charles C Thomas, 1966, pp 15-24.

3. Stewart FW. Experiences in spontaneous regression of neoplastic disease in man. Tex Biol Med 10:239-253, 1952.

4. Bennett WH. Some peculiarities in the behavior of certain malignant and innocent growths. Lancet 1:3-7, 1899.

5. Levison VB. Spontaneous regression of a malignant melanoma. Br Med J 1:458-459, 1955.

6. Bodurtha AJ. Spontaneous regression of malignant melanoma. In: Clark WH, Goldman LI, Mastrangelo JM (eds), Human Malignant Melanoma. New York, Grune \& Stratton,
1979, pp 227-241.

7. Spitler LE. Malignant melanoma. J Invest Dermatol 67:435-441, 1976.

8. McGovern VJ. Spontaneous regression of melanoma. Pathology 7:91-99, 1975.

9. Smith JL, Stehlin JS Jr. Spontaneous regression of primary malignant melanomas with regional metastases. Cancer 18:1399-1415, 1965.

10. Matthews FS. Melanosarcoma of shoulder and nodes about shoulder after incomplete operation. Ann Surg 62:114-117, 1915.

11. Daland ME, Holmes JA. Malignant melanoma. N Engl J Med 220:651-660, 1939 
12. Pack GT. Note on the experimental use of rabies vaccine for melanomatosis. Arch Dermatol Syph 62:694-695, 1950.

13. Levi JE, Lewison EF. Malignant melanoma in a patient with ovarian agenesis: Case reports of prolonged survival. J Clin Endocrinol 12:901-907, 1953.

14. Sumner WC. Spontaneous regression of melanoma. Cancer 6:1040-1043, 1953.

15. Allen EP. Malignant melanoma, spontaneous regression after pregnancy. Br Med J 2:1067, 1955.

16. Sumner WC, Foraker AG. Spontaneous regression of human melanoma: Clinical and experimental studies. Cancer $13: 79-81,1960$.

17. Meyer HW. Cited by Everson TC, Cole WH. Ann Surg 144:366-383, 1956.

18. Vial AB, Coller FW. Cited by Everson TC, Cole WH. Spontaneous Regression of Cancer. Philadelphia, WB Saunders, 1966.

19. Boyd $W$. Spontaneous regression of cancer. J Can Radiol 8:45-49, 1957.

20. Vogler, WR, Perdue GD, Wilkins SA Jr. A clinical evaluation of malignant melanoma. Surg Gynecol Obstet 106:586-594, 1958.

21. Petersen NC, Bodenham DC, Lloyd OC. Malignant melanoma of the skin. Br J Plast Surg 15:49-94, 1962.

22. Baker HW. Spontaneous regression of malignant melanoma. Am Surg 30:825-829, 1964.

23. Cade S. Malignant melanoma. Ann R Coll Surg Engl 28:331-366, 1961.

24. McCredie J. Cited by Everson TC, Cole WH. Spontaneous Regression of Cancer. Philadelphia, WB Saunders, 1966.

25. Ellis FW. Cited by Everson TC, Cole WH. Spontaneous Regression of Cancer. Philadelphia, WB Saunders, 1966

26. Malleson N. Spontaneous regression of malignant mela- noma. Br Med J 1:668, 1955.

27. Block GE, Hartwell SW Jr. Malignant melanoma: A study of 217 cases. Ann Surg 154 (Suppl):88-101, 1961.

28. Blocker TB Jr. Cited by Everson TC, Cole WH. Ann Surg 144:366-383, 1956.

29. Foley WJ, Coon WW. Unusual clinical course in patients with malignant melanoma. Mich Med 69:763-766, 1970.

30. Doyle JC, Bennet RC, Newing RK. Spontaneous regression of malignant melanoma. Med J Aust 2:551-552, 1973.

31. Bulkley GB, Cohen MH, Banks PM, et al. Long-term spontaneous regression of malignant melanoma with visceral metastases. Cancer 36:485-494, 1974.

32. Maurer LH, McIntyre OR, Rueckert F. Spontaneous regression of malignant melanoma. Am J Surg 127:397-403, 1974.

33. The EJ, Eibergen R, Lamberts HB, et al. Immune phagocytosis in vivo of human malignant melanoma cells. Acta Med Scand 192:141-144, 1972.

34. Bodurtha AJ, Berkelhammer J, Kim $\mathrm{YH}$, et al. A clinical, histological and immunological study of a case of metastatic malignant melanoma undergoing spontaneous remission. Cancer 37:735-742, 1976.

35. Nathanson L. Spontaneous regression of malignant melanoma: A review of the literature on incidence, clinical features, and possible mechanisms. Nat Cancer Inst Monogr 44:67-76, 1976.

36. Ewing J. Neoplastic Diseases. Philadelphia, WB Saunders, $1940, \mathrm{p} 45$.

37. Cole WH. Spontaneous regression of cancer: The metabolic triumph of the host? Ann NY Acad Sci 230:111-141, 1974.

38. Rohdenburg GL. Fluctuations in the growth energy of malignant tumors in man, with special reference to spontaneous regression. J Cancer Res 3:193-225, 1918. 